\title{
Relation between asbestosis and bronchial cancer in amphibole asbestos miners
}

\author{
G K SLUIS-CREMER, B N BEZUIDENHOUT \\ From the Epidemiology Research Unit, Medical Bureau of Occupational Disease, PO Box 4584, Johannesburg \\ 2000, Republic of South Africa
}

\begin{abstract}
In a necropsy series of 339 amphibole asbestos miners heavy smoking, age, and the presence of asbestosis were significantly associated with the presence of bronchial cancer. Of the 35 cases of bronchial cancer, 24 were associated with asbestosis. Eleven cases of bronchial cancer occurred in men without asbestosis; all were smokers. Standardised proportional mortality rates indicated no excess of bronchial cancer in 302 exposed men without asbestosis whereas these rates were progressively raised in men with slight or moderate/severe asbestosis. Of the four exposure variables introduced separately into a logistic regression model, "years of exposure" made a small but significant contribution; "residence time" marginally failed to achieve a $5 \%$ level of significance. Two other exposure variables tested including cumulative fibre exposure (fibre years) made no significant contribution. In the absence of asbestosis at necropsy a bronchial cancer in a man exposed to asbestos is unlikely to be due to asbestos.
\end{abstract}

The question of whether the presence of parenchymal asbestosis is a necessary prerequisite to attribute a bronchial cancer to inhalation of asbestos is controversial. Some compensation authorities insist that asbestosis must be shown before compensation is granted. Furthermore, some authorities believe that the dose of respirable asbestosis dust that will cause bronchial cancer is about the same ${ }^{1}$ or even greater ${ }^{2}$ than that which will cause asbestosis.

The object of the present study was to determine if any parameters of exposure to asbestos dust exert any additional risk of developing bronchial cancer after allowing for the presence of asbestosis.

\section{Materials and methods}

A mortality study on all white men identified from company records who were employed by amphibole asbestos mines (crocidolite and amosite) in South Africa is being analysed. Records regarding employees were preserved by different companies from between 1945 and 1956. At the latter date the keeping of records became compulsory. Black employees were not considered in this study because of inadequacies of registration of causes of death and poor smoking and exposure data. Altogether 7318 men were identified and death certificates sought at the Department of the Interior. Of these, $1165(15.9 \%)$ had died by 31
December 1980 and their death certificates were obtained. Necropsies had been performed on 427 $(36.7 \%)$ of the men and the reports of pathologists (staff of the National Centre for Occupational Health) on macroscopic and histological findings in the lungs were available. These reports indicate whether asbestosis was present, its grade, and whether bronchial cancer was present (table 1).

Asbestosis was graded as follows: slight asbestosis implies organisation of alveolar spaces with some interstitial thickening due to collagen or reticulin with areas of normal lung. In moderate asbestosis changes are more extensive but less so than in pronounced asbestosis. Pronounced asbestosis implies organisation of alveolar spaces and fibrosis of alveolar walls to the extent that there is no normal lung or massive fibrosis even without the above. In all cases asbestosis bodies or fibres must be present.

An unmatched case referant design was adopted for the study. The cases were 35 individuals with bronchial cancer as identified by necropsy. Ten of the 35 cases had no mention of bronchial carcinoma on the death certificate, yet, in eight of these necropsy clearly proved that bronchial cancer was the cause of death. In two cases the cause of death was not so certain. In one there was a bronchial adenocarcinoma with metastases but evidence of extensive non-asbestotic fibrosis of the lungs leading to severe cor pulmonale. In the second case obstructive airways disease appeared to be the cause of death but a small oat cell 
Table 1 Cases of bronchial cancer and referents by smoking status and degree of asbestosis

\begin{tabular}{lcc}
\hline & Cases & Referents \\
\hline Smoking status: & No (\%) & No $(\%)$ \\
Never & $2(5 \cdot 7)$ & $35(9 \cdot 6)$ \\
Ex & $6(17 \cdot 1)$ & $36(9 \cdot 9)$ \\
Light & $5(14 \cdot 3)$ & $70(19 \cdot 2)$ \\
Moderate & $11(31 \cdot 4)$ & $175(48 \cdot 1)$ \\
Heavy & $11(31 \cdot 4)$ & $48(13 \cdot 2)$ \\
Total & 35 & 364 \\
Asbestosis: & $11(31 \cdot 4)$ & $291(79 \cdot 9)$ \\
None & $15(42 \cdot 9)$ & $54(14 \cdot 8)$ \\
Slight & $9(25 \cdot 7)$ & $19(5 \cdot 2)$ \\
Moderate/pronounced & 35 & 364 \\
Total & & \\
\hline
\end{tabular}

bronchogenic carcinoma was also found at necropsy. The latter two were included among the cases.

Data of smoking habits were not available in 28 men (none with bronchial cancer) and they were excluded from the analysis. The group for the study therefore comprised 399 men (table 1). The referents were the 364 men without bronchial cancer who had smoking data.

The files of the cases and referants kept by the Medical Bureau for Occupational Disease (MBOD) were searched for details of exposure to asbestos and other mining dust and for smoking habits. Smoking habit was taken as the number of cigarettes or equivalents for cigars or pipe recorded in the last MBOD clinical examination before death. Smoking status was categorised as never a smoker, ex-smoker (cessation more than two years before date of examination), current light smoker (1-9 cigarettes a day), current moderate smoker (10-19 cigarettes a day), and current heavy smoker ( 20 or more cigarettes a day) (table 1).

Years of exposure to asbestos and residence time (time of first exposure to date of death) were known from the MBOD files. Dose of asbestos was computed by multiplying the measured fibre/ml levels for each mine, occupation and calendar period by time a man had worked in each occupation, and summing the

Table 2 Means and standard deviations (SD) for age and exposure to asbestos by cases of bronchial cancer and referents

\begin{tabular}{|c|c|c|c|c|}
\hline & \multicolumn{2}{|c|}{ Cases $(n=35)$} & \multicolumn{2}{|c|}{ Referents $(n=364)$} \\
\hline & Mean & $(S D)$ & Mean & $(S D)$ \\
\hline $\begin{array}{l}\text { Age } \\
\text { Years exposure } \\
\text { Residence time } \\
\text { Fibre years } \\
\text { Residence TWD }\end{array}$ & $\begin{array}{r}59 \cdot 5 \\
11 \cdot 2 \\
21 \cdot 3 \\
73 \cdot 7 \\
1202 \cdot 2\end{array}$ & $\begin{array}{r}(8 \cdot 4) \\
(8 \cdot 2) \\
(7 \cdot 0) \\
(153 \cdot 7) \\
(2808 \cdot 0)\end{array}$ & $\begin{array}{r}51 \cdot 4 \\
4 \cdot 2 \\
14 \cdot 6 \\
23 \cdot 7 \\
385 \cdot 7\end{array}$ & $\begin{array}{r}(12 \cdot 1) \\
(6 \cdot 0) \\
(8 \cdot 2) \\
(88 \cdot 3) \\
(2163 \cdot 6)\end{array}$ \\
\hline
\end{tabular}

TWD $=$ Time weighted dosage. various exposures over his career and expressing 商e result as fibre years.

The residence time weighted dosage (resider TWD) as described by Finkelstein ${ }^{3}$ was also computed (table 2).

To model the effect of exposure to asbestos on the risk of developing bronchial cancer when adjusting the effects of smoking habits, age, and asbestosis, 商 unconditional logistic regression analysis was performed using the program "RISK."4

As exposure to asbestos was expressed in four wẩs (years of exposure, residence time, fibre years, a⿳亠口冋 residence TWD), four models were created to analyse each exposure variable uniquely with smoking, aģ̧, and asbestosis. For the categorical variables smoking and asbestosis, design (indicator) variables were generated to contrast each category with the baseline category (no smoking and no asbestosis respectived by the "partial" coding scheme. ${ }^{5}$

To test how adequately the models fitted the data, smoking, age, asbestosis, and the respective expostge to asbestos variables were entered in a stepwise manner in that order, and the goodness of fit $\chi^{2}$ wes tested for significance using the change in the log likelihood $\chi^{2}$ ratio. ${ }^{6}$ Odds ratios were determined from the regression coefficients as estimators of increased risk of bronchial cancer.

To test how the prevalence of bronchial cancegr ${ }^{\circ}$ in the three groups, no asbestosis, slight asbestosis aod moderate pronounced asbestosis, compared witst age, race, and sex standardised rate in the white male population of South Africa, three standardised proportional mortality rates (SPMR) were estimated.

\section{Results}

The fit of the model to the data improved as each of the variables smoking, age, and asbestosis was entered (table 3). The most significant contributor in predief-

Table 3 Goodness of fit $\chi^{2}$ values for the stepwise logistic regression analyses

\begin{tabular}{|c|c|c|c|c|c|}
\hline Model & Step & Term entered & $\begin{array}{l}\text { Improve- } \\
\text { ment in } \\
\text { LR } \chi^{2 \dagger}\end{array}$ & $\begin{array}{l}\text { Degree } \\
\text { of } \\
\text { freedom }\end{array}$ & $p_{\text {Value }} \stackrel{ }{\mathrm{D}}$ \\
\hline $\begin{array}{l}1 \\
2 \\
3 \\
4\end{array}$ & $\begin{array}{l}1 \\
2 \\
3 \\
4 \\
4 \\
4 \\
4\end{array}$ & $\begin{array}{l}\text { Smoking } \\
\text { Age } \\
\text { Asbestosis } \\
\text { Years exposure } \\
\text { Residence time } \\
\text { Fibre years } \\
\text { Residence TWD }\end{array}$ & $\begin{array}{l}10 \cdot 13 \\
14 \cdot 83 \\
30 \cdot 1 \\
6 \cdot 36 \\
2 \cdot 78 \\
0 \cdot 11 \\
0.0\end{array}$ & $\begin{array}{l}4 \\
1 \\
2 \\
1 \\
1 \\
1 \\
1\end{array}$ & $\begin{aligned} 0.04 三 \\
0.000 \mathrm{D} \\
<0.0009 \\
0.01 \mathrm{~N} \\
0.10 \mathrm{O} \\
0.74 \mathrm{~W} \\
1.0\end{aligned}$ \\
\hline
\end{tabular}

*Each model contained smoking, age, asbestosis, and the exposure variable in step 4.

tThe maximised log likelihood ratio $\chi^{2}\left(\right.$ LR $\left.\chi^{2}\right)$ statistic at STER with only a constant in the model was -118.59 with 1 DF. The ER $\chi^{2}$ reported is the improvement in the fit of the model to the dat over the model fitted at the previous step. 
Table 4 Estimates of relative risk (odds ratios) for each of the four models with $95 \%$ confidence intervals (95\% CI)

\begin{tabular}{|c|c|c|c|c|}
\hline & Model I & Model 2 & Model 3 & Model 4 \\
\hline & Odds ratio $(95 \% \mathrm{CI})$ & Odds ratio $(95 \%$ CI) & Odds ratio (95\% CI) & Odds ratio $(95 \% \mathrm{CI})$ \\
\hline $\begin{array}{l}\text { Smoking: } \\
\text { Never } \\
\text { Ex } \\
\text { Light } \\
\text { Moderate } \\
\text { Heavy } \\
\text { Age }\end{array}$ & $\begin{array}{l}1.0 \\
3.06(0.52-18.04) \\
2.99(0.47-18.88) \\
3.39(0.63-18 \cdot 19) \\
11.25(2.01-62.98) \\
1.07(1.03-1.13)\end{array}$ & $\begin{array}{l}1.0 \\
2.45(0.43-14.05) \\
2.46(0.40-15.02) \\
2.43(0.47-12.48) \\
9.94(1.83-53.91) \\
1.06(1.01-1.11)\end{array}$ & $\begin{array}{l}1.0 \\
2.60(0.45-14.88) \\
2.47(0.40-15.22) \\
2.51(0.48-13.08) \\
9.40(1.72-51.36) \\
1.07(1.02-1.12)\end{array}$ & $\begin{array}{l}1.0 \\
2.63(0.46-15.06) \\
2.55(0.42-15.66) \\
2.57(0.49-13.42) \\
9.53(1.74-52.16) \\
1.07(1.02-1.12)\end{array}$ \\
\hline $\begin{array}{l}\text { Asbestosis: } \\
\text { None } \\
\text { Slight } \\
\text { Moderate/pronounced } \\
\text { Exposure variable* }\end{array}$ & $\begin{array}{l}1.0 \\
4.45(1.64-12.08) \\
5.20(1.60-16.88) \\
1.08(1.02-1.14)\end{array}$ & $\begin{array}{l}1.0 \\
5.63(2 \cdot 15-14.73) \\
8.53(2.92-24.91) \\
1.05(0.99-1.11)\end{array}$ & $\begin{array}{l}1 \cdot 0 \\
7 \cdot 40(2 \cdot 98-18 \cdot 40) \\
9 \cdot 85(3 \cdot 28-29 \cdot 58) \\
1.0\end{array}$ & $\begin{array}{l}1.0 \\
7.60(3.06-18.84) \\
10.40(3.57-30 \cdot 32) \\
1.0\end{array}$ \\
\hline
\end{tabular}

*Exposure variable refers to years of exposure to asbestos, residence time, fibre years, and residence TWD for models $1,2,3$, and 4 respectively.

ing the likelihood of being a case of bronchial cancer was asbestosis with an improvement in the likelihood ratio $\chi^{2}\left(L R \chi^{2}\right)$ of 30.1 with 2 DF $(p=0.0001)$ after adjusting for the effects of smoking habits (LR $\left.\chi^{2}=10 \cdot 1 ; 4 \mathrm{DF}, \mathrm{p}=0.04\right)$ and age (LR $\chi^{2}=14.83$; $1 \mathrm{DF}, \mathrm{p}=0.001)$. In model 1 years of exposure to asbestos emerged as an additional contributor to the likelihood of being a case $\left(\mathrm{LR} \chi^{2}=6.36 ; 1 \mathrm{DF}\right.$, $\mathrm{p}=0.01$ ). No other measurement of exposure emerged as an additional risk factor.

The pattern of odds ratios remained consistent for each of the four models (table 4). Raised odds ratios were found for heavy smokers, age, both categories of asbestosis, and years of exposure. In model 1, for example, the estimated increase in risk of developing bronchial cancer was 11.25 for heavy smoking (95\% CI, 2.01; 63.0), for each increasing year of age 1.07 $(1.03 ; 1 \cdot 13)$, for slight asbestosis $4.45(1.64 ; 12.08)$, moderate pronounced asbestosis $5 \cdot 2(1.60 ; 16.88)$, and for each additional year of exposure to asbestos 1.08 $(1.02 ; 1 \cdot 14)$. The latter extrapolates to $2.08(1.20 ; 3.59)$ for every additional 10 years of exposure to asbestos.

The SPMRs shown in table 5 are calculated both for the 35 cases of bronchial cancer proved by necropsy and the 25 cases of bronchial cancer as certified on the death certificate.

Table 5 SPMRs for the number of cases of bronchial cancers observed by grade of asbestosis

\begin{tabular}{lrrrrrrr}
\hline Asbestosis & No & \multicolumn{1}{c}{ Expected } & Observed & SPMR & Observed & SPMR \\
\hline None & 302 & 12.4 & 11 & 88.7 & 8 & 64.5 \\
Slight & 69 & 3.6 & 15 & 416.7 & 11 & 305.6 \\
$\begin{array}{l}\text { Moderate/ } \\
\text { pronounced }\end{array}$ & 28 & 1.6 & 9 & 562.5 & 6 & 375.0 \\
\hline
\end{tabular}

*Cases of bronchial cancer proved by necropsy.

tCases of bronchial cancer as certified on death certificate.

SPMR = Standardised proportional mortality rates.

\section{Discussion}

This analysis indicates that of the variables of interest, the presence of asbestosis and indices of exposure (years of exposure, residence time, fibre years, and residence TWD), the presence of asbestosis was by far the most significant risk factor to being a case of bronchial cancer, $\mathrm{p}<0.0001$ (table 3).

The only index of exposure that remained significant after the effect of the presence of asbestosis had been taken into consideration was years of exposure $\mathrm{p}=0.01$ (table 3 ). The odds ratio, 1.08 , was small but the $95 \%$ CI were narrow, $1 \cdot 02-1 \cdot 14$ (table 4 ).

Cumulative asbestos respirable dust exposure expressed as fibre years had no significant effect and the effect of residence time $(p=0.1$, OR $1.05(0.99$ $1 \cdot 11)$ remained doubtful.

Kipen et al recently reported that all 138 cases of lung cancer for whom they were able to obtain a tissue specimen had asbestosis on histology. ${ }^{7}$ The cases arose out of the large prospective mortality study of asbestos insulation workers studied by Selikoff et al. ${ }^{8}$ Unfortunately no information on duration or intensity of exposure was given in this paper but exposure was probably prolonged.

In rats Wagner et al found that there was a positive association between asbestosis and lung tumours in a large experiment in which the animals had been exposed to clouds of various mineralogical types of asbestos for periods varying from one day to two years. ${ }^{9}$ The animals with tumours had significantly more asbestosis than those without ( $p<0.001$ ). Even rats with minimal or slight asbestosis had a significantly higher rate of tumours than those without asbestosis if they had survived at least 600 days. On the other hand, rats with no asbestosis had an incidence of tumours no higher than unexposed controls.

There is some evidence that the presence and 
profusion of irregular opacities on the radiograph correlate with the risk of bronchial cancer, though there is probably still a small risk when the radiograph is normal. ${ }^{10}$

Liddell and McDonald have reported that men with 20 years or more employment in the lower dust concentrations showed no statistically significant excess mortality for any condition except pneumoconiosis and conclude that most but not necessarily all cases of lung cancer attributable to asbestos would show opacities before death. ${ }^{.1}$

A histological diagnosis of asbestosis as presented in this paper should give a more accurate estimate of the association between exposure to asbestos, asbestosis, and bronchial cancer.

The SPMR for both the 35 cases proved by necropsy and the 25 cases certified as bronchial cancer on the death certificate show no excess bronchial cancer in the group without asbestosis whereas there is an excess in those with asbestosis. The excess increases with the severity of the asbestosis found at necropsy (table 5).

In conclusion this study suggests that asbestos caused bronchial cancer is almost always associated with some degree of histologically demonstrable asbestosis. It must be emphasised that these results should not affect compensation bodies dealing with living subjects exposed to asbestos as slight asbestosis is commonly, and moderate asbestosis occasionally, undetected radiologically. ${ }^{12}$

We thank Dr W P D Logan and Dr P A Hessel for advice on the analysis. We acknowledge the work of the pathologists of the National Centre for
Occupational Health which generated the data analysed in this paper.

\section{References}

1 The Royal Commission on Matters of Health and Safety aris from the use of asbestos in Ontario. Report. Vol 1. Otta Ontario Ministry of the Attorney General, 1984:283.

2 Weill H. Asbestos. A summing up. In: Wagner JC, ed. Biologeal effects of mineral fibres. Vol 2. Lyon: International Agency for Research on Cancer, 1980:867-73. (Publ No 30.)

3 Finkelstein MM. A study of dose response relationships $\overrightarrow{\mathbf{C}}$ asbestosis associated disease. $\mathrm{Br} \mathrm{J}$ Ind $\mathrm{Med}$ 1985;42:319-25. -

4 Thomas DC. "RISK" program. Montreal: McGill University, 1980.

5 Lemeshow S, Hosmer Jr DW. Estimating odds ratios wigh categorically scaled covariates in multiple logistic regressign analysis. Am J Epidemiol 1984;119:147-51.

6 Breslow NE, Day NE. Statistical methods in cancer research 1 . The analysis of case control studies. Lyon: International Agency por Research on Cancer, 1980:193-246.

7 Kipan HM, Lilis R, Suzuki Y, Valciukas JA, Selikoff IJ. Pulmơ ary fibrosis in asbestosis insulation workers with lung canceroa radiological and histopathological evaluation. $\mathrm{Br} \mathrm{J}$ Ind $\mathrm{MP} d$ 1987;44:96-100.

8 Selikoff IJ, Hammond EC, Seidman H. Mortality experience Pf insulation workers in the United States and Canada 1943-19.0. Ann NY Acad Sci 1979;330:91-116.

9 Wagner JC, Berry G, Skidmore JW, Timbrell V. The effects of the inhalation of asbestos in rats. Br J Cancer 1974;29:252-69. 6

10 Bohlig H, Jacob G, Muller H. Die Asbestose der Lungen. Stuttgeff: Georg Thieme Verlag, 1960:60.

11 Liddell FDK, McDonald JC. Radiological findings as prestets of mortality in Quebec asbestos miners. Br J Ind $\bar{Q}$ e d 1980;37:257-67.

12 Sluis-Cremer GK, Hessel PA, Hnizdo E. Factors influencing reading of irregular opacities in a radiological survey of asbestos miners in South Africa. Arch Environ Health (in press). 